\title{
An Analysis of the Fusion of Japanese Tea Ceremony and Japanese Language and Literature
}

\author{
Xiangmei Meng ${ }^{1}$ \\ ${ }^{1}$ Shandong College of Tourism \& Hospitality, Shandong, 250200
}

Keywords: Japanese tea ceremony; Japanese language and literature; fusion

\begin{abstract}
With the acceleration of the process of world economic integration, the speed of cultural integration is also rapidly increasing. Regardless of the form of culture, the role of language cannot be replaced for cultural exchanges, and language has enabled the construction of a cultural system. Japanese language and culture are associated with tea culture, integrated with each other to enrich Japan's national culture. This paper briefly analyzes the content and characteristics of Japanese tea culture, combines Japanese language and literature with simplicity, and analyzes the relationship between the two, to provide some help for the study of Japanese culture.
\end{abstract}

\section{Introduction}

China's tea culture has a long history, and Japanese tea ceremony is deeply influenced by China's tea culture and Buddhist thought. In the Japanese tea ceremony, the core idea of "Jade tea is blind" comes from Buddhist culture. With the recognition of tea culture by Japanese people, the rapid development and popularization of tea culture can not only reflect the tea culture in daily life, but also profoundly reflect the Japanese language and literature in Japan. There are many Chinese and Japanese scholars who integrate tea ceremony and language culture. A study was conducted, which promoted the development and integration of tea culture in the two countries and accelerated the integration of Japanese tea ceremony and Japanese language and literature.

\section{The Content and Main Features of Japanese Tea Culture}

Japanese Tea Ceremony values the words "and harmony, solitude, and silence," and promotes tea culture as a fusion of religion, philosophy, aesthetics, and ethics. Our culture is closely related to Japanese culture. In many ways, we can see places where cultural fields are intertwined. Japanese tea ceremony art is also developed under the influence of Chinese tea culture. Therefore, in-depth study of Japanese tea ceremony art can deepen the understanding of the connotation of the cultural system can also be a reflection of the far-reaching influence of Chinese tea culture on Japanese tea culture [1].

According to Japanese literature, during the Tang Xuanzong period, the Japanese's oranges brought back tea seed and planted tea trees from Datang through learning to plant tea and tea. After several improvements, the scale gradually expanded. In the Nara era, the earliest tea company, Hiyoshi Tea Garden, was formed. Later, the empty sea monk Dongdu crossing Datang, found that tea also has a therapeutic effect, which has made rapid progress in the tea ceremony in Japan, the empty sea monk also learned the Tang Dynasty tea cooking techniques, and brought the tea set back to Japan in the peaceful period During the Edo period, the two peak periods of tea ceremony development ushered in. During this period, the Chiaki-e of the Warring States period increased the emphasis on natural and simple tea culture and advocated that the tea ceremony should be free from the constraints of foreign objects and made the development of Japanese tea ceremony. Later, Japan absorbed and digested the Tang Dynasty tea culture, formed the Matcha Road and the Senchao Road, and gradually developed into a modern tea ceremony culture. In the 1980s, Japan's tea culture began to return, and thousands of thousands of ancestral tea ancestral temples visited China many times [2].

Japanese tea ceremony was established on the basis of "daily tea and food", and gradually 
formed a comprehensive form of culture and art. Tea is not only a material enjoyment, but also can play a role in the cultivation of temperament. With the improvement of Japan's tea ceremony by Chien-Hsiu, the spirit of tea ceremony in Japan has also been promoted and its development has been further improved. At that time, the tea ceremony had its own tea room. Before entering the tea room, visitors needed a clean hand, shoes off, and even if they had to step into the tea room, which foot was very particular. There will be tea for the tea in the tea room, and there will be special water for the tea room. The tea will also be used to control the guests' tea. It is necessary to pay tribute to the tea [3]. In addition, the decoration style of the tea room also changes with the changing seasons. The flower arrangement of the tea room needs to be replaced with the change of the four seasons. The light in the poor room should also be soft, so that the light will not be particularly strong during the day and it can make people enjoy the taste of the taro in a quiet atmosphere. It should be noted that in the tea room, there is usually no exchange of topics related to economics and politics, so the atmosphere of the tearoom will be relaxed and pleasant, allowing people to enjoy the worldly ease of enjoying tea. Drinking tea is not only a method of picking up customers, but also an elegant pastime. It can be a cup of tea for everyone, or a tea for the guests alone. Different forms represent different meanings [4].

Japanese tea ceremony culture is consistent with people's life rhythm and lifestyle. The rich connotation of tea ceremony culture also reflects the cultural characteristics of Japan. Japanese tea ceremony pays attention to the pursuit of inner peace. This is also due to the influence of Buddhist ideas on Japanese tea ceremony. When you drink tea, you must be calm and detached, and your ideas should be detached. The decoration of the tea room should be arranged in a layout that is simple and elegant. At the same time, the Japanese tea ceremony aspires to the harmony of nature and achieves "tea chan." It is necessary to feel comfortable and comfortable in the process of tea tasting. In Japan, the reason why tea ceremony is deeply loved by Guo Min is very much related to Taoism's "inaction" thought. By drinking tea, people can purify people's hearts, get rid of impetuousness, and stay away from the intrigues of people in the society. The talking and laughing in the tea room will make people feel happy and experience the pleasantness of life [5].

\section{The Development History and Main Features of Japanese Language and Literature}

Japanese language culture condenses the essence of national culture and is the external interpretation of literary ideas and culture. Through the research and analysis of Japanese language and literature, the value of Japanese language and literature can be maximized, thus further studying the language literature and tea culture.

\subsection{History of Japanese Language and Literature Development}

If you want to study Japanese language and literature, you have to start with the Japanese language study. Japan did not have its own text at first and recorded incidents by knots. After the Chinese text was introduced to Japan, the Japanese combined their own recording habits to improve the culture. Today's Japanese language is formed, but Chinese pronunciation and Chinese characters are still preserved in Japanese. Although there are many literary forms in Japanese language and literature, most of them are short and subtle, and they can express profound meanings with concise words. This is particularly evident in poetry. Later Western literature was introduced. Japanese literature is more abundant in connotation [6].

\subsection{Analysis of the Basic Content of Japanese Language and Literature}

Japanese language and literature contain many forms, including: Japanese short poems, haiku, lianju, witty, essays, novels, etc. Most poems end with vowels, and haiku emphasizes rhyme. At the same time, Japanese language and literature are greatly influenced by the Chinese classical literary works, but the forms are quite unique. Specifically speaking, novel prose emphasizes linguistic grace, and there must be logic before and after; essays are more realistic content and can be real and dull. In the following period, short stories quickly developed in Japan, and a large number of writers emerged. Through simple narratives and profound analysis of the characters, short stories occupied 
a place in the Japanese language school. Dividing Japanese language and literature according to time can be divided into: an ancient literature; b the world; c modern literature; $d$ modern literature; e modern literature, and each period has a corresponding representative, formed a different feature.

\subsection{The Main Features of Japanese Language and Literature}

Most of Japanese language and literature are short and refined, and their expressions are concise but they can convey delicate and abundant information. Many poetic forms of literary works have a simple structure. Just like a weak-looking girl with a strong inner heart, she seems to express her freedom but has a rich connotation. He can communicate with readers emotionally and realize his true feelings through plain and plain text. This reflects social issues and arouses readers' sympathy. Through the analysis of the characteristics of Japanese language and literature, we can find many elements related to the Japanese cultural system, so we must innovate Japanese language and literature [7].

\section{The Value Analysis of the Fusion of Japanese Tea Ceremony and Japanese Language and Literature}

Japanese language culture is characterized by rigorous and exquisite, exudes unique charm and attracts many language lovers. Japanese tea ceremony and Japanese language and literature have their own cultural characteristics. The combination of the two will produce different sparks. Japanese tea ceremony art and Japanese language and literature play an important role in the Japanese cultural system. As people recognize the role of cultural values and urgently realize the construction of a pluralistic system, it is necessary to realize the Japanese tea ceremony art and Japanese language and literature.

Japanese tea ceremony and Japanese language and literature all reflect the pursuit of inner peace. Although concise and subtle, the inner culture shows an atmosphere. This cultural connotation and Chinese culture complement each other, and while retaining the true appearance of things, through appropriate play, A more vivid display of the objective world. The spiritual pursuit of the tea ceremony is like the sublimation of the spirit of tea tasting and the washing of the soul. Japanese literature also has the same characteristics. In the works, the thoughts of the works are reflected as much as possible, and the foreign elite culture is absorbed in conjunction with the development characteristics of the era, gradually developed a unique tea culture and Japanese language and literature. Japanese tea ceremony and Japanese language and literature, as important contents of the Japanese cultural system, are not only reflected in the elements, but also embody the charm of cultural fusion in the blend of emotion and value [8].

Although the Japanese tea ceremony culture originated in ancient China, it was later developed through the influence of Japanese local culture and has developed into a cultural feature that is completely different from that of the Chinese tea ceremony culture. In the process of making and tasting tea, Japanese tea ceremony can show a steady cultural heritage and is a symbol of Japanese culture. In the history of Japanese language and literature, both in film and television works and literary works, there will be scene descriptions related to tea culture. The most representative book is "Eating Tea and Health," as the first book on tea, the medicinal properties of tea are recorded. At the same time, this book records the development and prevalence of Japanese tea culture during the Song Dynasty. The combination of Japanese tea ceremony and Japanese language and literature is like a Zen master. It is rigorous, atmospheric, and quiet. At the same time, it is like a craftsman. It tells the Japanese tea culture how to develop to today's situation through the language, and pays attention to each development. The details, recording the history of the development of ethnic cultures, the fusion of the two makes the expression of Japanese language more characteristic. The tea ceremony culture has made the development of Japanese language and literature more rigorous. At the same time as tea tasting, the exchange of language can make people feel calm and peaceful, reflecting the seriousness and solemnity of the Japanese, and thus highlighting the glittering point of Japanese culture. This is also Japan.

Through the study of Japanese tea culture, it is not difficult to see that the Japanese tea culture 
has formed a unique culture and dissolves the national spirit, making the Japanese language mellow like a cup of tea. For Japanese tea ceremonies, the cultural values they contain are based on multiculturalism. Of course, if you want to develop and pass on the Japanese tea ceremony art, you need the entire nation to contribute because the inheritance of the national culture cannot be accomplished overnight. It is necessary for the younger generation to know that the national culture is the basis for the existence of the nation, from the previous songwriter. The combination of arts and knights' paths and the development of tea ceremonies into the current tea culture do not lack the spirit of "artisanship". They all need to be selected through appropriate cultural concepts. Therefore, Japanese language and literature play a role as a bridge, and can enrich Japanese tea culture. At the same time, on the basis of inheritance and development, we can innovate the elements of development and make the art of tea ceremony more literary. The Japanese people have a more comprehensive understanding of the tea culture system and have done their best to tea tasting. Therefore, in people's lives, the tea culture system and the public life are combined together to make the relationship between Japanese culture and tea. The expression of Japanese language fully embodies the integration of tea elements in the Japanese cultural system. No matter whether it is from the perspective of the concept of life value or the concrete connotation of life, it can be embodied. As a carrier of Japanese cultural heritage, Japanese language has played a significant role in forming specific cultural connotations and promoting the development of the Japanese tea culture system.

\section{Conclusion}

To sum up, when the tea culture first spread and developed in Japan, it also gradually formed the prosperity of today's tea culture through language exchange. The linguistic features of Japan can also reflect the conciseness of the tea culture. Through the spread of tea culture through language, it is possible to further develop specific language expressions for tea, such as "matcha" and "fried tea". It is often used by Japanese citizens to integrate into Japanese, and it also affects the language expression habits of many people. In the Japanese tea culture, apart from the tea itself, there are some extended meanings, and it also has regional characteristics and national characteristics, which make it form a regional culture, and also have some degree of understanding of the concept of tea culture. In addition, tea and tea as a product of development of tea culture, convenient for people to communicate at the same time, but also contains endless wisdom, so the development of Japanese tea culture and Japanese language and literature are closely related, but also require people to further study its culture.

\section{References}

[1] Ge Huiling. Analysis of the Fusion of Japanese Tea Ceremony and Japanese Language and Literature [J]. Fujian Tea, 2017, 39(9): 287-288.

[2] Shen Yingli, Wang Fei, Chen Tingting. Exploring the History of Japanese Tea Culture in Japanese Expressions [J]. Fujian Tea, 2017, 39(11):385-386.

[3] Song Lin. Analysis of the Fusion of Japanese Tea Ceremony and Japanese Language and Literature [J]. Fujian Tea, 2017, 39(8): 300-301.

[4] Xia Guofeng. Japanese Tea Translation under the Influence of Japanese Tea Culture[J]. Fujian Tea, 2018(2):316-317.

[5] Liu Yi. On the Practical Application of Tea Culture in Japanese Teaching [J]. Fujian Tea, 2017, 39(12):379-379.

[6] Wang Xiaomin. A Study on the Course Setting of Japanese Tea Culture in Undergraduate Courses_-Taking Tianjin Foreign Studies University as an Example[J]. Asia-Pacific Education, 2016(26):252-253. 
[7] Zhao Hongtao. The development of Japanese tea ceremony from the idiomatic expression of borrowing tea in Japanese[J]. Fujian Tea, 2017, 39(3):324-325.

[8] Yi Hongyan. The Analysis of the Relationship between Japanese Tea Culture and Japanese Expression [J]. Fujian Tea, 2018(2): 375-376. 